\title{
Moving forward: Tackling stigma in a Tanzanian community
}

Laura Nyblade

Kerry MacQuarrie

Gideon Kwesigabo

Aparna Jain

Lusajo Kajula

See next page for additional authors

Follow this and additional works at: https://knowledgecommons.popcouncil.org/departments_sbsr-hiv

Part of the Demography, Population, and Ecology Commons, Health Policy Commons, Immune System Diseases Commons, International Public Health Commons, Medicine and Health Commons, Public Health Education and Promotion Commons, Social Policy Commons, and the Virus Diseases Commons

How does access to this work benefit you? Let us know!

\section{Recommended Citation}

Nyblade, Laura, Kerry MacQuarrie, Gideon Kwesigabo, Aparna Jain, Lusajo Kajula, Fausta Philip, William Henerico Tibesigwa, and Jessie K. Mbwambo. 2008. "Moving forward: Tackling stigma in a Tanzanian community," Horizons Final Report. Washington, DC: Population Council. 


\section{Authors}

Laura Nyblade, Kerry MacQuarrie, Gideon Kwesigabo, Aparna Jain, Lusajo Kajula, Fausta Philip, William Henerico Tibesigwa, and Jessie K. Mbwambo 


\section{Hprizons}

\section{Moving Forward: \\ Tackling Stigma in a Tanzanian Community}

International Center for Research on Women

Muhimbili University of Health and Allied Sciences

Muhimbili National Hospital

National Institute of Medical Research

Horizons Program 


\title{
Moving Forward: Tackling Stigma in a Tanzanian Community
}

\author{
Laura Nyblade ${ }^{1}$, Kerry MacQuarrie ${ }^{1}$, Gideon Kwesigabo ${ }^{2}$, \\ Aparna Jain ${ }^{1}$, Lusajo Kajula ${ }^{2}$, Fausta Philip ${ }^{3}$, \\ William Henerico Tibesigwa ${ }^{4}$, Jessie Mbwambo ${ }^{3}$
}
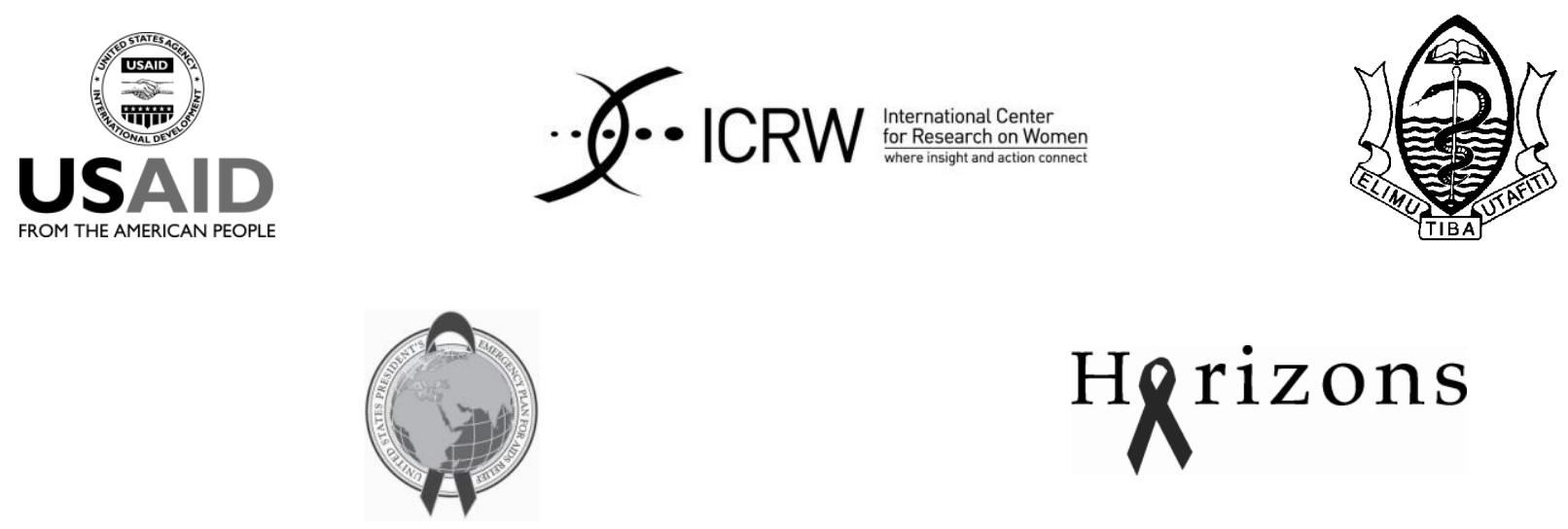

Program affiliations at the time of the study:

${ }^{1}$ International Center for Research on Women

${ }^{2}$ Muhimbili University of Health and Allied Sciences

${ }^{3}$ Muhimbili National Hospital

${ }^{4}$ National Institute of Medical Research 


\section{Acknowledgments}

This study would not have been possible without close collaboration with Kimara Peer Educators and Health Promoters Trust (KPE) and Family Health International, Tanzania. The study team would like to especially thank Julie Pulerwitz and Ellen Weiss of the Horizons Program, and Lisanne Brown of Tulane University for all their support in this effort. The project was funded by USAID.

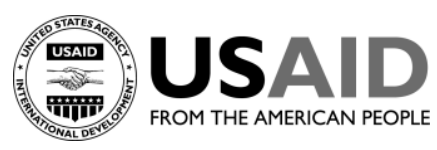
necessarily reflect the views of USAID or the United States Government.
This study and final report were made possible by the President's Emergency Plan for AIDS Relief and the generous support of the American people through the United States Agency for International Development (USAID) under the terms of Cooperative Agreement No. HRN-A00-97-00012-00. The contents are the responsibility of the Horizons Program and do not

Published in March 2008.

\section{(2) Population Council}

The Population Council is an international, non-profit, nongovernmental institution that seeks to improve the well-being and reproductive health of current and future generations around the world and to help achieve a humane, equitable, and sustainable balance between people and resources. The Council conducts biomedical, social science, and public health research and helps build research capacities in developing countries. Established in 1952, the Council is governed by an international board of trustees. Its New York headquarters supports a global network of regional and country offices.

Copyright (C) 2008. The Population Council Inc.

Suggested citation: Nyblade, Laura, Kerry MacQuarrie, Gideon Kwesigabo, Aparna Jain, Lusajo Kajula, Fausta Philip, William Henerico Tibesigwa, and Jessie Mbwambo. 2008. "Moving forward: Tackling stigma in a Tanzanian community," Horizons Final Report. Washington, DC: Population Council.

This document may be reproduced in whole or in part without permission of the Population Council provided full source citation is given and the reproduction is not for commercial purposes. 


\section{Table of Contents}

Executive Summary 1

$\begin{array}{ll}\text { Introduction } & 5\end{array}$

$\begin{array}{ll}\text { Defining stigma } & 5\end{array}$

Prevalence of stigma and its impact on the HIV response $\quad 5$

$\begin{array}{ll}\text { Stigma-reduction approaches } & 6\end{array}$

$\begin{array}{ll}\text { Measuring stigma } & 7\end{array}$

$\begin{array}{ll}\text { Study objectives and conceptual framework } & 7\end{array}$

$\begin{array}{ll}\text { Methods } & 11\end{array}$

$\begin{array}{ll}\text { Study design } & 11\end{array}$

Data collection and samples $\quad 11$

$\begin{array}{ll}\text { Measures } & 13\end{array}$

$\begin{array}{ll}\text { Analysis } & 14\end{array}$

Indicator testing $\quad 15$

$\begin{array}{ll}\text { Results } & 16\end{array}$

People recognize stigma. 16

Both fear and value drivers of stigma remain high. 16

Fear-driven stigma is hard to shift despite high knowledge of HIV. 17

Individuals exposed to KPE reported less stigmatizing attitudes. 18

Community members observed more instances of discrimination/enacted stigma 18

Balozi leaders are a promising entry point for intervention $\quad 20$

KPE program did not reduce stigma community wide. $\quad 21$

The stigma indicators performed solidly over time. 22

New measures for care and recognizing stigma are useful improvements. 24

Discussion and Next Steps $\quad 26$

$\begin{array}{ll}\text { Lessons learned } & 27\end{array}$

$\begin{array}{ll}\text { References } & 28\end{array}$

$\begin{array}{ll}\text { Appendix } & 31\end{array}$ 



\section{Executive Summary}

Although there are a growing number of programs working to reduce stigma, a gap remains in evaluated programs, particularly at the community level. Documentation and evaluation of these pioneering efforts is essential so that successful program elements can be replicated and scaled up. To help fill this gap, the International Center for Research on Women (ICRW), the Muhimbili University College of the Health Sciences (MUCHS), the Horizons Program of Population Council, and Family Health International (FHI) conducted an evaluation of a community-based effort to reduce stigma in a peri-urban community in Tanzania. They also re-tested a set of stigma indicators recommended from a prior field test in Tanzania to see how they performed over time.

The Kimara Peer Educators' and Health Promotors Trust Fund (KPE) implemented the program which consisted of training and capacity building on stigma for all KPE staff volunteers (56), people living with HIV who were part of KPE support groups (24), and community leaders known as balozi leaders (10); support to all trainees in developing their own creative, low-cost, and sustainable ways to address stigma in their regular, ongoing activities; and incorporation of stigma reduction into KPE counseling for persons with HIV and families affected by HIV.

Survey data were collected pre- and post-intervention and triangulated against intervention process data collected throughout the life of the intervention, and qualitative data were collected after the intervention was complete. The baseline and endline community surveys were conducted using a cluster area sampling technique with probability proportional to size method. To be eligible, individuals had to be 16 years of age or older and a resident in Kimara ward for at least three months. At baseline, the sample was 978 (53 percent women and 47 percent men), and at endline it was 910 (56 percent women and 44 percent men). Baseline data collection occurred from April to June 2004 and endline data collection from May to September 2006.

The outcome measures in the quantitative survey focused on the three drivers of stigma being tackled by KPE's program:

- Recognition of stigma (or lack thereof).

- Fear of acquiring HIV through everyday contact with infected people.

- Values linking people with HIV to immoral behavior (i.e., shame and blame).

The post-intervention qualitative data were collected via in-depth interviews and focus groups discussions with a range of individuals who directly or indirectly were involved in KPE programming, including people living with HIV and their caretakers and confidants; balozi leaders, other community leaders, KPE staff volunteers, and community members.

Ethical clearances for the study were obtained from the MUCHS Research and Publications Committee, the Dar es Salaam Regional Administrative Secretary (RAS), and the Population Council. Community assent was granted from the district Ward Executive Officer, and at the balozi level. All respondents provided informed consent prior to being interviewed. 


\section{${ }^{H}{ }^{\text {rizons }}$}

\section{Results}

\section{People recognize stigma.}

Recognition of stigma increased among Kimara respondents over the study period. Approximately 87 percent of respondents surveyed at endline recognized and understood the Kiswahili word for stigma, "kunyanayapaa" and were able to give a definition of it, as compared to 73 percent at baseline $(\mathrm{p}<0.01)$. Similarly, the frequent use of the word "kunyanyapaa" throughout the post-intervention qualitative transcripts (appears in 89 percent of the transcripts) demonstrated respondents' understanding of the word as meaning stigma. Another indication that recognition of stigma is now high is that respondents were readily able to provide examples of enacted stigma. Eighty-four percent of respondents in the endline survey were able to provide at least one example of stigma, as compared to 29 percent at baseline.

\section{Both fear and value drivers of stigma remain high.}

Both fear and value-driven stigma increased significantly between baseline and endline. Shame and blame - the two types of value-based stigma - were about 9 percentage points higher in 2006 than they were in 2004. Blame was then, and continues to be, more prevalent than shame, with more than 8 out of 10 respondents agreeing with one of four blame statements. Not only did the proportion of the sample reporting fear-driven stigma increase by more than 13 percentage points, but the number of fears each respondent held is also higher. At endline, respondents reported 2.39 specific fears as compared to 1.97 fears at baseline, although the difference is not statistically significant.

\section{Fear-driven stigma is hard to shift despite high knowledge of HIV.}

Overall, HIV and AIDS knowledge increased from baseline to endline. The proportion of respondents with correct knowledge of prevention rose from 24 percent at baseline to 45 percent at endline $(\mathrm{p} \leq .01)$. Correct knowledge of transmission and correct in-depth knowledge were higher than prevention knowledge at baseline and rose more modestly. Yet, consistently two-thirds of those with correct knowledge, be it of transmission, prevention, or in-depth knowledge, held at least one fear.

\section{Individuals exposed to KPE activities reported less stigmatizing attitudes.}

Respondents exposed to the KPE program showed better stigma outcomes than their non-exposed counterparts at endline. Exposed respondents almost universally recognized stigma (96 percent), and they less frequently agreed with shame or blame statements. A smaller proportion of exposed respondents reported fear of HIV and, on average, reported fewer fears (1.89 versus 2.52, NS) compared to nonexposed respondents. Logistic regression analyses that controlled for potentially confounding factors showed a trend suggesting that those exposed to KPE were less likely to hold a shame attitude, but the difference was not statistically significant. 


\section{Community members observed more instances of discrimination/enacted stigma.}

Observations of enacted stigma increased between the baseline survey and endline survey. This was consistently the case across all four forms of enacted stigma, with the largest increases in loss of identity, which more than doubled, and institutional stigma. While this could reflect an actual increase, it could also reflect an increased ability among respondents to identify stigmatizing acts as a result of their increased recognition of what stigma is.

\section{Balozi leaders are a promising entry point for intervention.}

The anti-stigma training provided balozi leaders with new learning and skills, which led to significant personal reflection and action. The qualitative transcripts show that change is most clearly apparent among this group in both value- and fear-driven stigma. The program also catalyzed key actions among the balozi leaders, such as rallying their communities to respond to stigma when it happens and making referrals to appropriate services. That the program was so transformative for the participating balozi leaders indicates promise for positive outcomes from wider training of balozi leaders and other types of community leaders.

\section{KPE's program did not reduce stigma community wide.}

In comparing levels of the stigma drivers in clusters where KPE was present to clusters where it was not, the study found no statistically significant difference at the community level. For example, on average, the number of fears of respondents living in clusters where KPE was present (2.36) was about equal to the number of fears of respondents residing in clusters where KPE was not active (2.53). The mere presence of KPE's stigma activities was not sufficient to cause ripple effects and foster positive outcomes among individuals not directly exposed to the intervention.

\section{The stigma indicators performed solidly over time.}

Results from reliability and validity tests indicate that the quantitative measures used in this study to assess fear-, shame-, and blame-driven stigma are reliable, valid, and appropriate for evaluation purposes.

\section{Discussion and Next Steps}

The findings of this study present a mixed, but hopeful, picture for a way forward in tackling stigma at the community level. In the face of what appears to be rising stigma in the community (Kimara) in general, respondents exposed to the KPE program had better stigma outcomes than their non-exposed counterparts at endline. In particular, there was a trend toward reduced value-driven stigma (i.e., shame) among exposed Kimara residents compared to non-exposed residents. Enacted stigma, or discrimination, that was observed by respondents was reported to increase over time, particularly in areas where KPE was active, which may be due to increased recognition of stigma and hence increased reporting. On the community level, as opposed to the individual level, the evaluation did not demonstrate change, perhaps due to an insufficient level of coverage and/or length of the intervention. 


\section{${ }^{H}$ rizons}

Based on this experience, several key lessons learned are already being applied as KPE moves forward. The first is that tackling stigma requires that the individuals tasked with doing this undergo personal change. The participatory training approach and the activities in the toolkit, Understanding and Challenging Stigma: A Toolkit for Action (Kidd and Clay 2003), worked well in this respect and are key to providing the tools and space to process, reflect, and learn about stigma to become an anti-stigma advocate within one's own sphere of influence. The second is to start by focusing stigma-reduction efforts on a smaller, more manageable geographical area. The third is to add a specific anti-stigma component KPE's portfolio of activities, in addition to integrating stigma messages into all ongoing program activities, due to concerns that the stigma messages may have been too diffuse.

Fourth, the positive results of training the balozi leaders, in particular the ability of these leaders to influence their constituencies, points to engaging community opinion leaders (e.g., political, religious, and youth leaders, and health care workers) as a promising way forward for scaling up stigma-reduction at the community level. KPE has already secured funding to expand the training of additional balozi leaders as well as to begin working with new groups of community leaders (e.g., faith leaders). 


\section{Introduction}

Stigma and discrimination, along with gender inequality, have been identified by UNAIDS as major and neglected barriers to effective responses to HIV (UNAIDS 2006b). Meeting the ambitious goal set by the international community of universal access to comprehensive HIV prevention programs, treatment, care, and support by 2010 (UNAIDS 2006a), will require rapid, effective scale-up of services. As UNAIDS notes, this will mean dramatic improvements in HIV programs and more effective approaches to stigma and discrimination. Although there are a growing number of programs working to reduce stigma, including many that use the media and that focus on health care settings, a gap remains in evaluated programs, particularly at the community level. Documentation and evaluation of these pioneering efforts is essential so that successful program elements can be replicated and scaled-up. To help fill this gap, this report presents key findings of an evaluation of a community-based effort to reduce stigma in a peri-urban community in Tanzania, as well as the results of ongoing work to refine a set of stigma program indicators.

\section{Defining Stigma}

Building on Goffman's (1963) seminal work on stigma, illness-related stigma has recently been defined as a social process (Link and Phelan 2001) which can reinforce relations of power and control (Parker and Aggleton 2003). Link and Phelan (2001) describe a four-step process of stigmatization that culminates in status loss and discrimination for the stigmatized. Thus, the ultimate effect of stigma, as noted by Goffman (1963), is the reduction of the life chances of the stigmatized through discriminatory actions. Deacon (2006) notes that disadvantages stemming from stigma goes beyond what are often understood as discriminatory actions. These can include "unjustified beliefs in immunity against disease" for those who do not know their HIV status, and for people living with HIV they can include internalized stigma, lowered self esteem, depression, and changes in behavior (e.g., not taking advantage of services and life opportunities) because of the expectation or fear of stigma. In this study, discrimination is not conceptualized as separate from stigma, but the end result of the stigma process - enacted stigma. This term refers to the negative effects that devalue individuals and reduce their quality of life and life chances, which is a broader concept than discrimination used by the legal and human rights communities (Carael et al. 2000).

\section{Prevalence of Stigma and its Impact on the HIV Response}

HIV stigma is globally prevalent. Worldwide, researchers have documented that people living with HIV are subject to job loss, school expulsion, ostracism, violence, lack of care and support, labelling of hospital files and beds, and loss of property (Brown et al. 2003; APN+ 2004; Yoddumnern-Attig. et al. 2004; Kalichman. et al. 2005; Ogden and Nyblade 2005; Mahendra et al. 2006; Oanh et al. 2008). In a recent study in Tanzania, 63 percent of women and 50 percent of men living with HIV had recently experienced stigma, and 59 percent of health providers surveyed reported observing stigma at their workplace (Tanzania stigma-indicators field testing group 2005). Stigma also operates within families, communities, institutions such as health care facilities and places of employment, in the media, and in government policies (Ogden and Nyblade 2005; Heijnders and van der Meij 2006; Oanh et al. 2008). 


\section{${ }^{H}{ }^{\text {rizons }}$}

A comparative study conducted in Ethiopia, Tanzania, Vietnam, and Zambia (Ogden and Nyblade 2005) identified four major forms of stigma:

- Physical stigma like isolation and violence.

- Social isolation and loss of identity.

- Verbal stigma.

- Institutional stigma that includes loss of livelihood and housing or differential treatment in public settings.

Numerous studies document the negative impact of stigma on HIV programs and services across the prevention to care and treatment continuum. Stigma is associated with poor uptake of preventive services, including under- or non-participation in educational meetings and counseling (Campbell et al. 2005); low intention to take preventive measures (Kalichman et al. 2006); and reduced participation in programs to prevent mother-to-child transmission (Nyblade and Field 2000; Bond et al. 2002). Fear of stigma deters people from testing for HIV (Kalichman et al. 2005; Madan et al. 2006) or disclosing their status (White and Carr 2005; Liu et al. 2006; Wolfe. et al. 2006), which are critical entry points for prevention, treatment, and care services. Stigma is connected with postponing or rejecting care, traveling outside local communities for care to prevent breaches of confidentiality, and non-adherence to medicines (Campbell et al. 2005; Liu et al. 2006; Mills 2006).

\section{Stigma-reduction Approaches}

Although evaluation data are limited, a recent review of stigma-reduction interventions concludes that the most promising approaches combine education with empowerment of and contact with people living with HIV (Brown et al. 2003). Interventions that use only one approach are less apt to be effective.

Various studies suggest that standard educational strategies to improve knowledge, when used alone, have limited effectiveness on stigma (Campbell et al. 2005; Chen et al. 2005; Kalichman et al. 2005;

Kalichman et al. 2006). However, participatory education that goes beyond improving knowledge to encourage people to reflect on their own attitudes and actions is more effective for catalyzing change (Ogden and Nyblade 2005; Hong et al. 2006). This is especially effective when people living with HIV are also included as participants or facilitators. A multi-country research study (Nyblade et al. 2003) recommends the following principles for all stigma reduction interventions:

- Create greater recognition about stigma: that it exists, what it looks like, how it is harmful, and the role each person has in reducing it.

- Recognize and challenge myths, misconceptions, and fears surrounding how HIV is transmitted by fostering in-depth, applied knowledge about all aspects of HIV and AIDS through a participatory and interactive process.

- Provide safe spaces to discuss the beliefs that fuel value-driven stigma that results in blame, shame, and internalized stigma.

- Ensure a central, safe, and meaningful role for people living with HIV that results in greater awareness among the target audience of their life experiences.

These principles and the promising approaches recommended in the intervention review (Brown et al. 2003) guided the development of the intervention whose evaluation is the subject of this report. 


\section{Measuring Stigma}

A review by Nyblade (2006) notes that stigma measures have focused on the fear-based dimension of stigma by assessing HIV knowledge or hypothetical willingness to interact with people living with HIV. A few studies noted in this review have included measures of value- or socially-driven stigma, typically examining responsibility, shame, and blame for contracting HIV. A working group of experts convened by the U.S. Agency for International Development (USAID), worked from 2002 to 2004 to develop a set of stigma indicators for program evaluation, incorporating improvements on commonly used measures (Nyblade and MacQuarrie 2006). These indicators were field-tested in Tanzania in 2004 and provided a set of reliable and validated program indicators to measure stigma, which are now used in this program evaluation (Tanzania stigma-indicators field testing group 2005).

\section{Study Objectives and Conceptual Framework}

This study had two inter-related objectives: to evaluate the Kimara Peer Educators' and Health Promoters Trust Fund's (KPE) anti-stigma program and to re-test stigma indicators recommended from the field test in Tanzania - to see how they performed over time (see Appendix 1). The study partners were the International Center for Research on Women (ICRW), the Muhimbili University College of the Health Sciences (MUCHS), the Horizons Program (implemented by the Population Council and partners), and Family Health International (FHI).

\section{Conceptual framework}

The intervention and its evaluation are based on the recommendations of a multi-country research study, which highlighted the need to address three programmatically actionable drivers of stigma (Nyblade et al. 2003). These are:

- Lack of recognition of stigma.

- Fear of acquiring HIV through everyday contact with infected people.

- Values linking people with HIV to immoral behavior (i.e., social stigma).

The intervention design was based on the assumption that to significantly reduce stigma experienced in a community (enacted stigma) and thereby the associated fear of stigma which impedes people's willingness and ability to access HIV services, these underlying drivers must be tackled first.

Figure 1 provides a simplified schematic to illustrate the posited trajectory for change for programs focused specifically on reducing HIV-related stigma. The framework recognizes that stigma occurs within a wider social context, and that together with individual characteristics, this context will influence antistigma program efforts. The framework also assumes that change in the drivers of stigma will take time, as stigma is deeply entrenched in social, gender, and sexual norms. Changing these norms and the societal structures that maintain them is a process that occurs over time. Therefore, the horizon for documenting anti-stigma efforts and any resultant changes in outcomes like VCT and disclosure will necessarily be long-term. 


\section{${ }^{H}{ }^{\text {rizons }}$}

Figure 1 Intervention Framework for Stigma Reduction

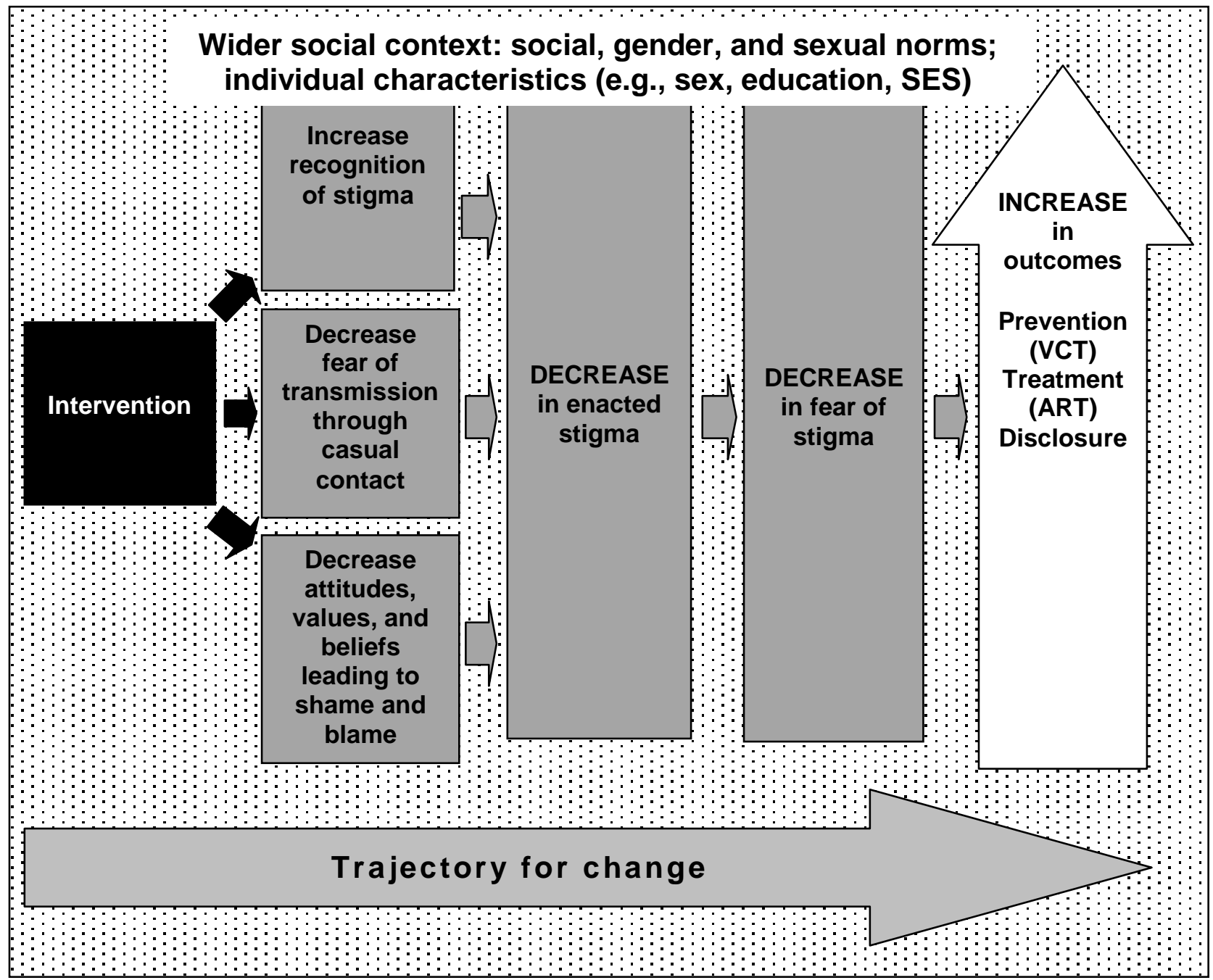

However, there are clear starting points for action to reduce stigma, as identified above, with measurable results possible in the short term. Therefore, this study focuses not on the larger context, but on the specific, immediately actionable drivers of stigma that KPE's program focused on: increasing recognition of stigma; addressing fears of acquiring HIV through everyday contact with infected people; and reducing the blame and shame driven by linking people with HIV to immoral behavior.

\section{Intervention description}

For the past ten years, Kimara Peer Educators and Health Promoters Trust (KPE) programs in Kinondoni Municipality, Dar-es-Salaam, have implemented a comprehensive set of HIV prevention and care activities and services. They include peer education, community education and mobilization, voluntary HIV counseling and testing, home-based care, counseling and support for people living with HIV, and orphan and vulnerable children support. 
In addition to supporting formative research on stigma in 2001-2003, KPE was one of 50 stakeholder groups involved in the development of a research-based stigma-reduction tool, Understanding and Challenging Stigma: A Toolkit for Action (Kidd and Clay 2003). From March 2004-2006, KPE used a two-year REACH program grant (USAID-funded through PACT) to begin stigma-reduction activities in Kinondoni, a large district that encompasses Kimaraward, a mixed-income, peri-urban suburb of Dar es Salaam, where KPE is located. This report summarizes the key findings from the initial two-year intervention.

The objectives of the KPE stigma-reduction program were to:

1. Ensure that all KPE staff volunteers, select members of KPE support groups of people living with $\mathrm{HIV}$, and an initial core of community leaders referred to in this report as balozi $i^{1}$ leaders, had the skills necessary to recognize, challenge, and carry out a program to reduce stigma.

2. Conduct community sensitization and mobilization, and foster social change for stigma by incorporating stigma reduction into all of KPE's ongoing activities, and by supporting all those trained to share their knowledge and speak out on stigma.

3. Empower people living with HIV and their families in Kinondoni community to overcome internal (self) stigma, challenge stigma, and be actively involved in reducing stigma in their community.

To meet these objectives, KPE carried out the following three complementary activities:

1. Provided training and capacity building on stigma to all KPE staff volunteers (56), people living with HIV who were part of KPE support groups (24), and balozi leaders (10). The KPE staff volunteers included peer educators, home-based care workers, and counselors. The training was conducted over two weeks and used participatory methods included in the Swahili translation of the stigma-reduction toolkit (Kidd and Clay 2003). It focused on each of the three stigma drivers (see Conceptual Framework) by:

- Creating awareness of stigma: what it looks like; why it is important to reduce it from an individual, family, and community perspective; and that each person has a role to play in reducing stigma.

- Addressing the myths and misconceptions about transmission of HIV and the resulting fears of contracting HIV through casual contact.

- Providing safe and non-threatening spaces to delve into the norms and values that underlie sociallydriven stigma leading to judgment, blame, and shame.

- Action planning for each team (e.g., home-based care workers, peer educators, balozi leaders) to develop a strategy to incorporate stigma reduction into their activities.

2. Provided support to all trainees in developing their own creative, low-cost, and sustainable ways to address stigma and incorporating them into all their regular, ongoing activities. In addition to the training, KPE staff, volunteers, and balozi leaders were supported through regular, ongoing supervision by KPE senior staff over the two-year intervention period.

Incorporating stigma reduction into everyday activities took several forms. KPE revised all communication materials (e.g., skits, songs, dances, pamphlets) to ensure that they were not inadvertently stigmatizing. KPE incorporated specific stigma-reduction messages into skits and songs and developed new IEC materials that were specifically designed to address stigma. KPE used stop-start drama, participatory games, and the picture codes and silhouettes from Understanding and Challenging Stigma: A Toolkit for Action (Kidd and Clay 2003) and other newly- learned participatory techniques to engage a range of audiences and peer groups in discussions about stigma.

\footnotetext{
${ }^{1}$ A balozi is an administrative unit of approximately 10 households.
} 


\section{${ }^{H}$ rizons}

Balozi leaders incorporated discussions of stigma into routine community meetings with the households under their jurisdiction and placed stigma on the agenda of local political meetings.

3. Incorporated stigma-reduction into counseling for persons with HIV and families affected by HIV. The counseling focused on recognizing and overcoming stigma within the family, as well as internalized (self) stigma, with the eventual goal of people living with HIV and their families becoming empowered to challenge stigma as it happens; advocate for their rights to employment, housing, treatment, care, and support; and, where appropriate, become visible HIV-positive role models in the community.

KPE added stigma-focused support and counseling into ongoing group and individual counseling for people living with HIV. This occurred during home-based care visits and through targeted family counseling of 192 families caring for a person living with HIV. For example, when the home-based care team became aware of negative reactions by family members to a person living with HIV in the household, the team used exercises from the toolkit to facilitate dialogue about what the individual family members were experiencing and help those concerned to recognize the stigma, where it came from, what was causing it, and to work to reverse it. Counseling sessions frequently addressed family members' fears of contracting HIV through non-sexual contact with the person living with HIV or the items they had touched. The team also opened up dialogue to help people living with HIV and their families recognize and then address how stigma within families and internalized stigma impede access to care and support. 


\section{Methods}

\section{Study Design}

Survey data were collected pre- and post-intervention and triangulated against intervention process data collected throughout the life of the intervention, and qualitative data collected after the intervention was complete. The baseline survey was completed as part of a larger study field-testing stigma indicators for the general population, health providers, and people living with HIV (Tanzania stigma-indicators field testing group 2005). The endline survey and post-intervention qualitative data were collected under a project implemented by MUCHS and ICRW, in collaboration with Horizons and FHI.

Ethical clearances for the study were obtained from the MUCHS Research and Publications Committee, the Dar es Salaam Regional Administrative Secretary (RAS), and the Population Council. Community assent was granted from the district, Ward Executive Officer, and at the balozi level. Individual consent was obtained from all respondents prior to participation in the quantitative surveys and qualitative interviews.

\section{Data Collection and Samples}

\section{Quantitative data}

The baseline and endline community surveys were conducted using a cluster area sampling technique with probability proportional to size method. For each selected cluster, the study team randomly selected six households, and from each household, one eligible male and one female respondent. To be eligible, individuals had to be 16 years of age or older and have been a resident of Kimara ward at least three months. At baseline, 1,083 eligible respondents were selected for participation in the study, and 978 (53 percent women and 47 percent men) participated fully by responding to the administered questionnaire, giving a response rate of 90 percent. At endline, a total of 1,090 eligible individuals were selected for participation in the community survey and 910 (56 percent women and 44 percent men) participated fully by responding to the administered questionnaire, giving a response rate for the endline community survey of 84 percent. The sample sizes at baseline $(n=978)$ and endline $(n=910)$ were sufficient to detect a change of 10 percent in stigma attitudes of shame and blame with a power of 80 percent and confidence level of 95 percent. Baseline data collection occurred from April to June 2004 and endline data collection from May to September 2006. All survey data were double-entered, compared, and cleaned in EPIINFO v6.04 and exported to SPSS v11.

\section{Qualitative data}

The target populations selected for participation in the post-intervention in-depth interviews (IDIs) and focus group discussions (FGDs) encompassed a range of individuals who directly or indirectly were involved in KPE programming:

- People living with HIV: Individuals who were participating in KPE activities.

- Community members: Community members residing in Kimara ward in clusters where the balozi leaders were trained and not trained by the project, as well as those residing outside of Kimara Ward.

- Trained and untrained balozi leaders. 


\section{${ }^{H}$ rizons}

- Religious leaders: Christian and Muslim.

- KPE staff volunteers: These included counselors, home-based care workers, peer educators, and directors of KPE.

- Confidantes of people living with HIV: Individuals identified by people living with HIV as someone who knows their HIV status and who would be willing to be interviewed.

Table 1 gives the number of each group who participated in IDIs and the total number of FGDs held by group.

Table 1 Participation in qualitative data collection

\begin{tabular}{llcc}
\hline \multicolumn{1}{c}{ Target groups } & \multicolumn{1}{c}{ Sub-category } & \# IDIs & \# FGDs \\
\hline Balozis & Trained & 3 & 1 \\
& Un-trained & 2 & \\
People living with HIV & People living with HIV & 12 & 4 \\
and others & Confidantes & 5 & \\
& Family care takers & 3 & \\
KPE staff volunteers & Counselors, peer educators, and home- & & \\
& based care workers & 10 & \\
Religious leaders & KPE directors & 2 & \\
\multirow{2}{*}{ Community members } & Christian & 4 & \\
& Muslim & 2 & 3 \\
& Residing under untrained balozis & 3 & 3 \\
Total & Residing under trained balozis & 5 & 4 \\
\hline
\end{tabular}

All qualitative transcripts were tape-recorded, transcribed verbatim (with field notes and observations added), and translated. Data were managed and coded using NUDIST*6.

\section{KPE process data}

KPE's monitoring and process data include service statistics; staff diaries and logs documenting field activities, experiences, and interactions; trained balozi leader workplans; and quarterly reports. Service statistics were routinely gathered to monitor VCT services, home-based care visits, number of orphans and other vulnerable children supported, and participation in group counseling. Data were recorded into notebooks, analyzed, and displayed in KPE offices monthly for use and reference by all program staff. During the intervention, counselors of group therapy sessions, home-based care workers, trained balozi leaders, and peer educators maintained diaries. The diaries were compiled and summarized into a spreadsheet and included in quarterly reports. Trained balozi leaders' action plans and implementation workplans were used during supervision and follow-up visits to assist in problem-solving and strategizing upcoming events. 
In addition, several cluster-level variables were created from KPE process data and entered into the survey dataset to reflect KPE program coverage in the survey clusters. These variables indicate which respondents resided in clusters where intervention activities and KPE-trained balozi leaders were present.

\section{Measures}

The outcome measures in the quantitative survey focused on the three drivers of stigma being tackled by KPE's program:

- Recognition of stigma (or lack thereof).

- Fear of acquiring HIV through everyday contact with infected people.

- Values linking people with HIV to immoral behavior (i.e., social stigma).

The primary measure for recognizing stigma was a direct question asking if respondents knew the meaning of the Kiswahili word "kunyanyapa" (stigma). Respondents also provided a definition of "kunyanyapa" and described an example of stigma.

Fear was measured by asking if they feared HIV infection through 11 specific means (e.g., if you touch the sweat of a person with HIV or AIDS, if you eat food prepared by a person with HIV or AIDS). From these 11 items, the study team created an index and calculated the number of fears respondents held and compared their means. As a second summary measure, the study team calculated the proportion of respondents who had at least one fear.

Two components of value-driven or social stigma were measured: (1) shame (e.g., I would feel ashamed if I was infected with HIV); and (2) blame and judgment (e.g., HIV is a punishment for bad behavior). We asked respondents if they agreed, disagreed, or were neutral to seven attitudinal statements capturing shame (3 items) and blame and judgment (4 items). From these individual items, we calculated two summary measures: (a) agreement with at least one of three shame statements; and (b) agreement with at least one of four blame statements.

We also measured enacted stigma by asking respondents if they personally knew someone within their community who was stigmatized or discriminated against in the last 12 months because they were known or suspected of being infected with HIV. Observed enacted stigma was assessed through 17 individual items focused on four different manifestations of stigma: 1) Isolation — physical and social exclusion/violence; 2) verbal stigma; 3) loss of identity/role; and 4) loss of access to resources (institutional). A summary measure was created for each form of stigma and for observed enacted stigma overall (at least one of all 17 items). All of the individual stigma items used in the post-intervention survey can be found in Appendix 1.

Three different knowledge measures were used: transmission knowledge, prevention knowledge, and indepth knowledge. Respondents were knowledgeable about transmission if they knew that HIV was transmitted via sex, blood, and mother-to-child, and gave no incorrect answers. Respondents had correct knowledge of prevention if they mentioned abstinence, monogamy, condoms, and avoiding contaminated blood while not mentioning any wrong responses. Respondents were classified as having in-depth knowledge if they knew four of six facts about HIV: HIV and AIDS are different; AIDS has no cure; a healthy-looking person can have HIV; partners can be discordant; HIV can be passed from mother to child during pregnancy, delivery, and breastfeeding; and mother-to-child transmission does not occur 100 percent of the time. 


\section{Hgrizons}

\section{Analysis}

To evaluate KPE's anti-stigma program, the three sources of data (process, qualitative, and quantitative) were analyzed separately and then compared. The process data were used to determine program implementation and coverage. The qualitative data were analyzed to describe the "state of stigma" in Kimara, after KPE's official intervention ended, and assess KPE's anti-stigma program. To gain an understanding of the current state of stigma in Kimara, and to compare and contrast qualitative data with the results of the quantitative indicators, qualitative interviews were analyzed using a grounded theory approach (Ulin et al. 2002) and thematic analysis (Ryan and Bernard 2003). Analysis and coding of the data for key themes was an ongoing process, conducted as data was collected. Investigators, together with the data collection team, developed a codebook, which was revised periodically in an iterative process, to ensure consistency in coding over time and to add codes as new themes emerged from the data (MacQueen et al. 1998). Coding was done both in Kiswahili, by the interviewers, and in English, by a principal investigator. In all the transcripts, attention was focused on insights emerging around the key drivers of stigma: awareness; fear of contracting HIV through casual contact; and attitudes linked to blame, judgment, and morality. Further analysis was conducted on transcripts from interviews with people living with HIV participating in KPE activities such as group counseling and income-generating activities, to capture their perspectives of community-based stigma and experiences of being stigmatized.

The survey data were analyzed first to assess the reliability and validity of the stigma indicators over time (see below) and their ability to capture what was happening with stigma in a community exposed to a stigma-reduction intervention. Survey data were then analyzed to compare differences at the two points of time and between respondents exposed and not exposed to the anti-stigma intervention.

For the quantitative sample there were two exposure categories: exposed and non-exposed. Given that stigma was integrated into all KPE activities, a respondent was deemed exposed to the program if s/he:

- Participated in any KPE service (e.g., home-based care).

- Participated in/witnessed any KPE activity.

- Received information on HIV or stigma from KPE.

- Received information on HIV or stigma from a trained balozi leader.

- Participated in any meeting on HIV led by a trained balozi leader.

The first quantitative analysis for program evaluation was a baseline to endline comparison to assess changes over the period. The study team first compared the outcome (dependent) variables of interest for the whole sample at baseline against the whole sample at endline, and then among those respondents (1) not exposed to the intervention and (2) exposed to the intervention at endline for the key outcome variables to elicit general patterns of stigma in Kimara ward. Secondly, the study team compared those exposed to the intervention with those not exposed to the intervention at endline to determine if the presence of the intervention was associated with reduced levels of stigma.

Differences between proportions on dichotomous variables were assessed using the Pearson's Chi Square test. Differences between proportions within categories on multi-categorical variables, where numbers were smaller, were estimated with the Fisher's Exact test. Differences between means were assessed using Anova test. The study team identified significant differences at 95 percent and 99 percent confidence intervals.

Finally, the study team conducted multivariate statistical analysis to control for potential confounding factors. Three models were estimated, each with one of three stigma outcomes (shame, blame, fear of 
HIV transmission) as the dependent variable. The resultant confidence intervals around the odds ratios were deemed significant at 95 percent and 99 percent levels.

\section{Indicator Testing}

The stigma indicators testing involved three steps. First, the study team compared levels of stigma and its drivers obtained through the quantitative indicators at endline with the qualitative data describing the state of stigma currently in Kimara and how that differed by exposure to KPE activities. This analysis helped establish to what degree the measures reliably represented the magnitude of stigma present and captured change.

Secondly, the study team reconstructed the stigma indicators exactly as recommended from the initial indicators test and subjected them to the same battery of reliability and validity tests to determine if the measures are stable over time. Testing included assessment of variability, modified test-retest reliability, index construction and reduction of items to a minimal set, internal consistency reliability with factor analysis, and construct validity (testing associations with other known variables conceptually related to the new variable) (Tanzania stigma-indicators field testing group 2005). Thirdly, several new items were incorporated into the stigma measures. The study team added new items to the endline survey to address certain gaps and weaknesses identified in the indicators tested earlier in Kimara, and evaluated whether their inclusion improved the performance of the existing measures. Once the stigma measures' internal stability and ability to capture the experience of stigma within Kimara was established, the survey data were further analyzed to assess KPE's program. 


\section{Hgrizons}

\section{Results}

\section{People Recognize Stigma.}

Recognition of stigma increased among Kimara respondents over the study period. Approximately 87 percent of respondents surveyed at endline recognized and understood the Kiswahili word for stigma, "kunyanayapaa" and were able to give a definition of it, as compared to 73 percent at baseline $(\mathrm{p}<0.01)$. Similarly, the frequent use of the word "kunyanyapaa" throughout the post-intervention qualitative transcripts (appears in 89 percent of the transcripts) demonstrated respondents' understanding of the word as meaning stigma.

Another indication that recognition of stigma was high is that respondents were readily able to provide examples of enacted stigma. Eighty-four percent of respondents in the endline survey were able to provide at least one example of stigma, as compared to 29 percent at baseline $(\mathrm{p}<.01)$. More examples of stigma given in the qualitative data described fear of transmission of HIV as a driving force of stigma, though negative attitudes toward people with HIV stemming from moral and value judgments were present as well. Examples of stigma noted by respondents included gossiping, finger pointing, and physical isolation (e.g., not providing care or refusing to sit next to a person with HIV).

As I understand it, stigma is the fear that is in a person not infected with AIDS. There is a fear that sitting near or taking care of a person with AIDS will lead to one getting infected. So the person decides to leave the infected person and to sit far from them. It [stigma] is like someone isolating you.

Female, family caretaker

It [stigma] is where a person passes by and you talked about him/her, and when he/she turns he/she sees a group of about six people staring at them.

Male, community member

\section{Both Fear and Value Drivers of Stigma Remain High.}

The qualitative transcripts and quantitative data uniformly portray a clear picture that both fear and valuedriven stigma are still present in Kimara at high levels. Not only were they high, but they increased significantly between baseline and endline (see Figure 2). Shame and blame-the two types of valuebased stigma-were about 9 percentage points higher in 2006 than they were in 2004. Blame was then and continues to be more prevalent than shame, with more than 8 out of 10 respondents agreeing with at least one of four blame statements.

Not only did the proportion of the sample reporting fear-driven stigma increase by more than 13 percentage points, but the number of fears each respondent held was also higher. At endline, respondents reported 2.39 specific fears as compared to 1.97 fears at baseline, although the difference was not statistically significant. 
Figure 2 Fear and value drivers of stigma at baseline and endline

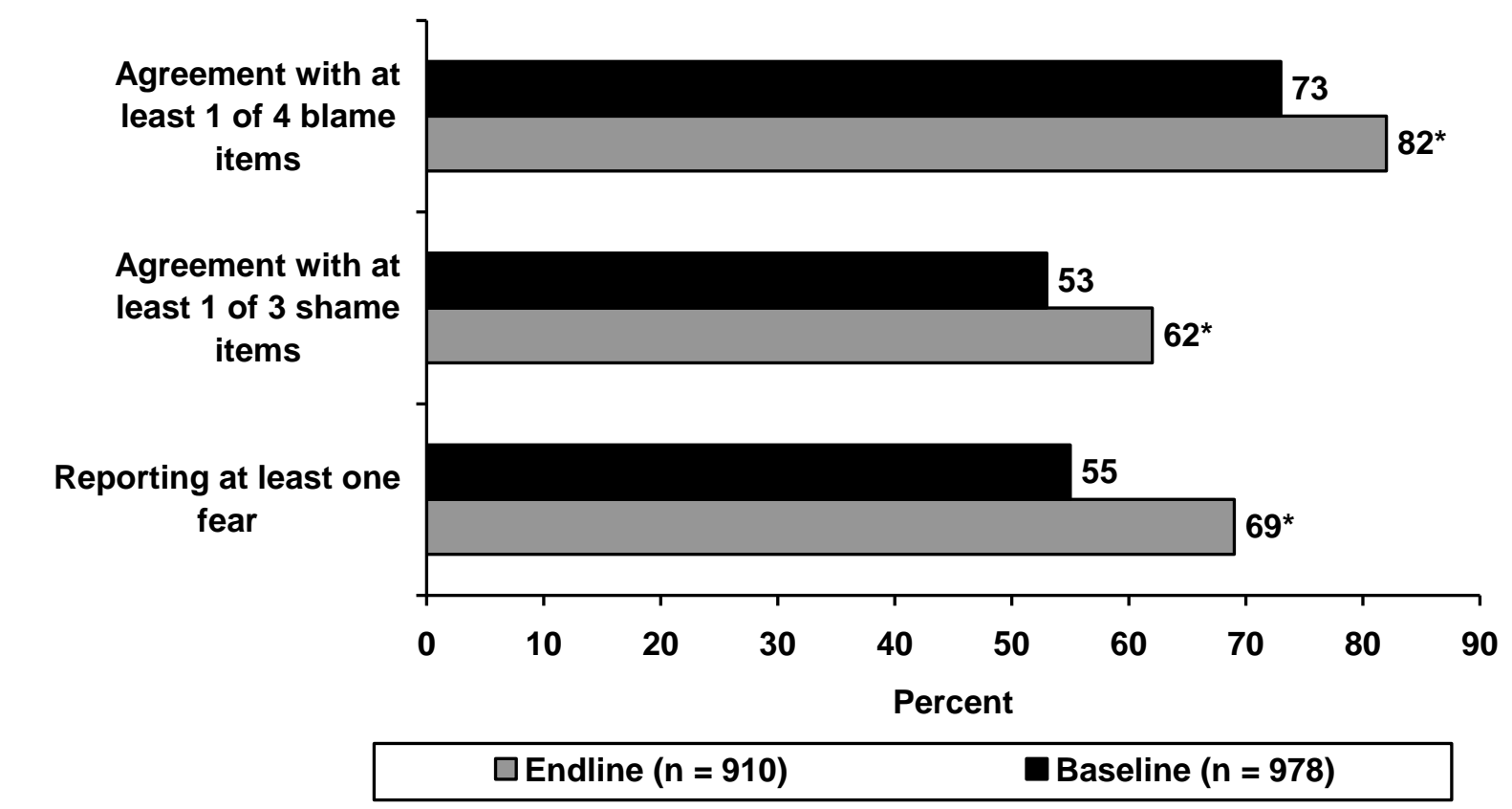

${ }^{*} \mathrm{p} \leq 0.01$

\section{Fear-driven Stigma is Hard to Shift Despite High Knowledge of HIV.}

Overall, HIV/AIDS knowledge increased from baseline to endline. The proportion of respondents with correct knowledge of prevention rose from 24 percent at baseline to 45 percent at endline $(\mathrm{p} \leq .01)$. Correct knowledge of transmission and correct in-depth knowledge were higher than prevention knowledge at baseline and rose more modestly. Yet, consistently two-thirds of those with correct knowledge, be it of transmission, prevention, or in-depth knowledge, held at least one fear.

Throughout the interview transcripts of respondents who were not directly involved in the initial KPE anti-stigma training, considerable fear is expressed around touching or sharing items with people living with HIV such as plates, food, spoons, and clothing. These fears of casual contact leading to HIV transmission drive individuals to alter their behavior by purposely avoiding contact with persons with HIV. Underlying these fears is particular concern about sweat contact, which coexists with stated knowledge that HIV cannot be transmitted through mere touching. The following quotes are representative of the type of fears expressed that fuel stigmatizing avoidance behaviors.

There you definitely will be infected [sitting on a bus next to a sweating person with HIV] because of the sweat. You would be infected because sweat is a bodily fluid. In that case you would already be infected.

Male, community members focus group

Eating with a person from the same plate and sitting next to the person. You will find maybe they will sneeze and the little germs jump from him to you and you end up getting them.

Male, community members focus group 


\section{${ }^{H}$ rizons}

\section{Individuals Exposed to KPE Reported Less Stigmatizing Attitudes.}

Respondents exposed to the KPE program showed better stigma outcomes than their non-exposed counterparts at endline (see Figure 3). Exposed respondents almost universally recognized stigma (96 percent) and they less frequently agreed with shame or blame statements. A smaller proportion of exposed respondents reported fear of HIV and, on average, reported fewer fears than those not exposed (1.89 versus 2.52 , NS).

Figure 3 Stigma drivers by exposure to KPE program at endline

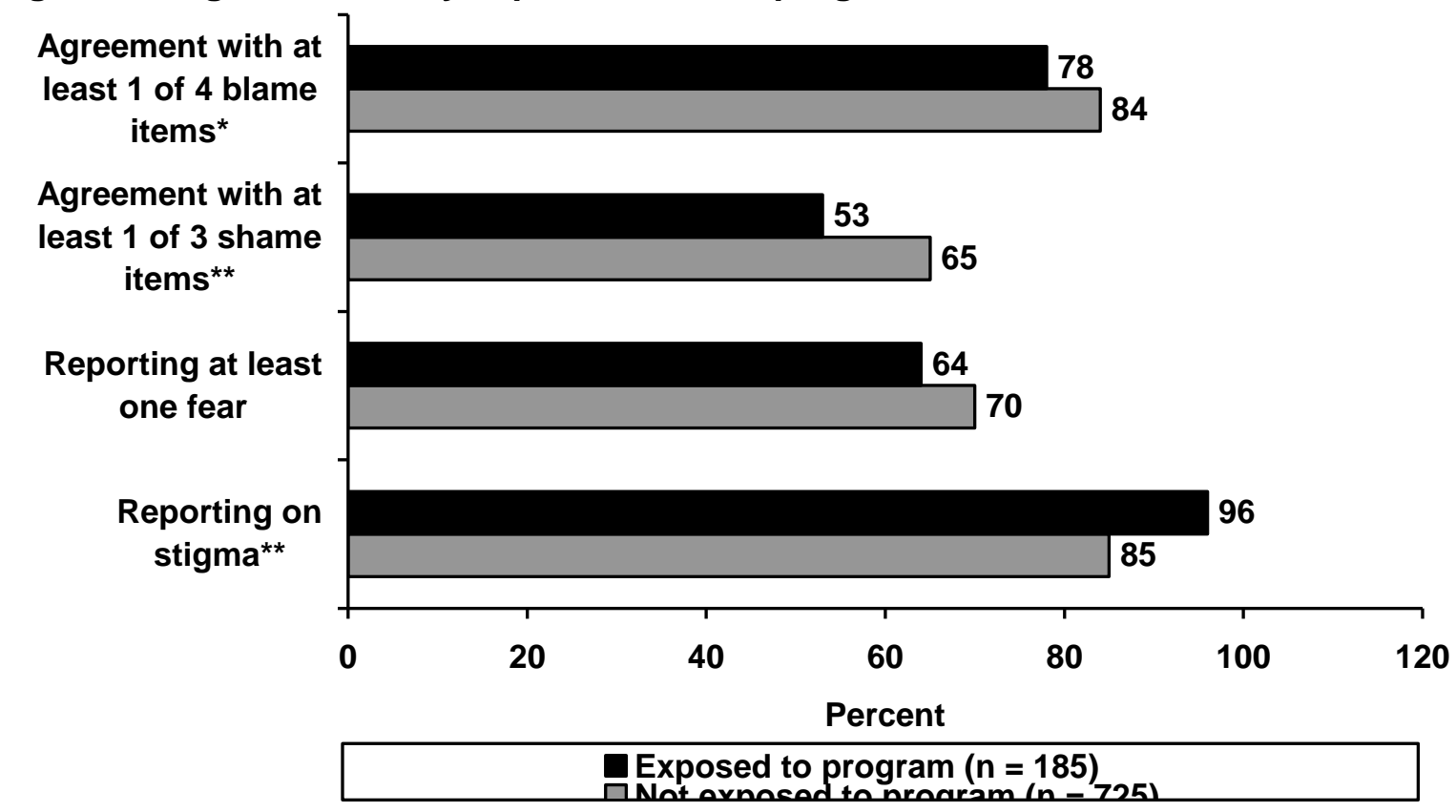

${ }^{*} \mathrm{p} \leq 0.05$

${ }^{* *} \mathrm{p} \leq 0.01$

To further isolate the effects due to KPE, the study team conducted logistic regression analyses that controlled for potentially confounding factors ${ }^{2}$ in Kimara ward. The analysis indicates that, net of other effects, there was a trend suggesting that those exposed to KPE were less likely to hold a shame attitude, but the difference was not statistically significant $(\mathrm{OR}=.707, \mathrm{p}<.10)$. There was a similar trend regarding blame attitudes and fear, but these effects were weaker.

\section{Community Members Observed More Instances of Discrimination/Enacted Stigma.}

As shown in Figure 4, observations of enacted stigma increased between the baseline survey and endline survey. This is consistently the case across all four forms of stigma, with the largest increases in loss of

\footnotetext{
${ }^{2}$ Beyond program exposure, our variable of interest, we included demographic and socioeconomic characteristics, media exposure, proximity to someone with HIV (as measured by knowing someone with HIV, having someone disclose personally to them, or knowing someone who died of AIDS), HIV testing experience, and HIV knowledge.
} 
identity, which more than doubled, and institutional stigma. While this could reflect an actual increase in observed stigma and discrimination, it could also reflect an increased ability among respondents to identify stigmatizing acts, as a result of their increased recognition of what stigma is.

\section{Figure 4 Enacted stigma at baseline and endline}

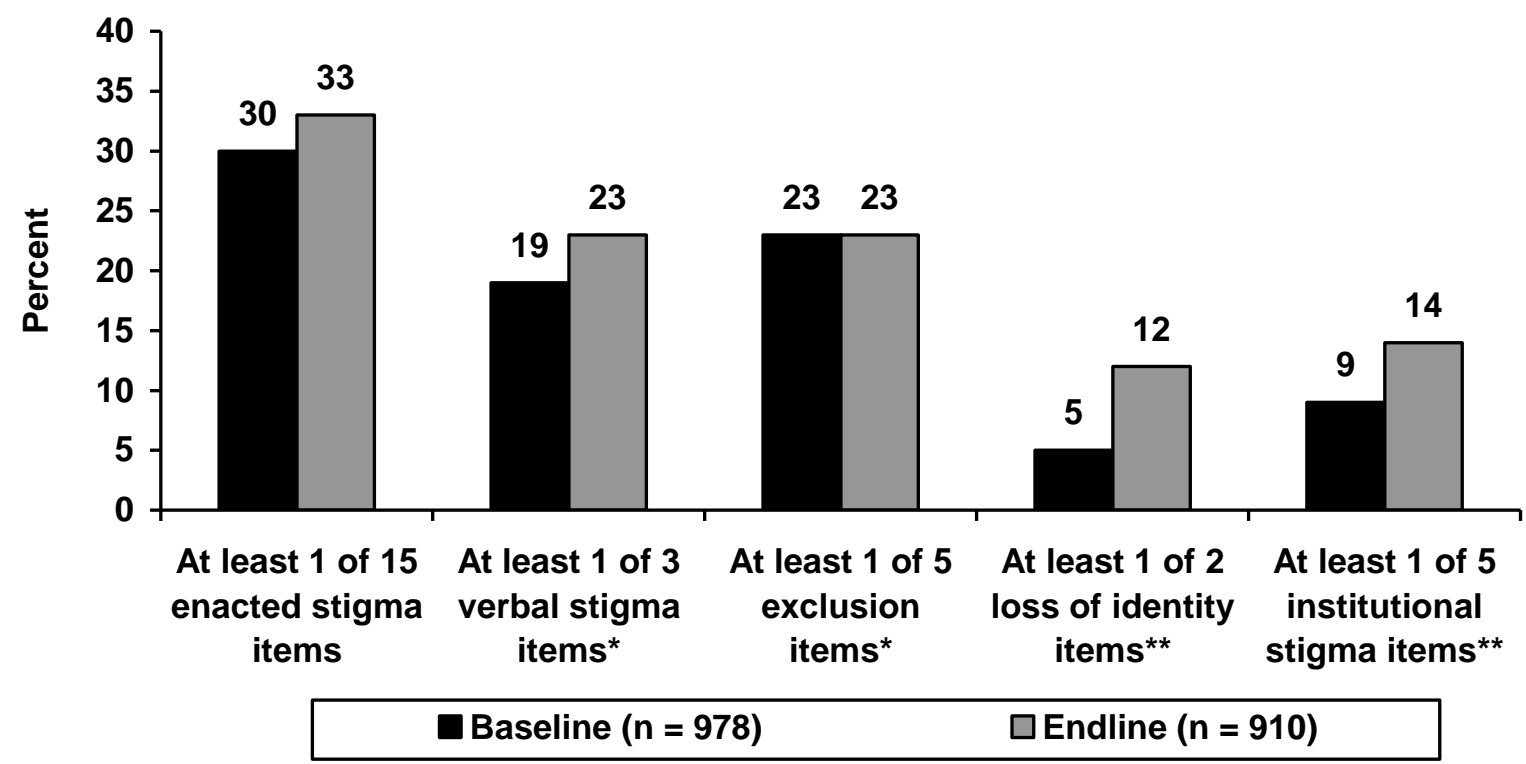

Note: \% reporting personal knowledge of incident occurring in Kimara in last 12 months ${ }^{*} \mathrm{p} \leq 0.05$

${ }^{* *} \mathrm{p} \leq 0.01$

This possibility is supported by the fact that observations of enacted stigma were higher in clusters where KPE's intervention was present and among those who were directly exposed to KPE's intervention (see Figure 5). For example, one in four respondents from clusters where KPE activities were present observed an example of verbal stigma in Kimara in the last year, as compared to 18 percent of those in other clusters $(\mathrm{p} \leq .05)$. Nearly 30 percent of those who participated in KPE activities witnessed someone being excluded because of their HIV status - the most common form of stigma - as compared to 25 percent of non-participants $(\mathrm{p} \leq .05)$. 


\section{Hgrizons}

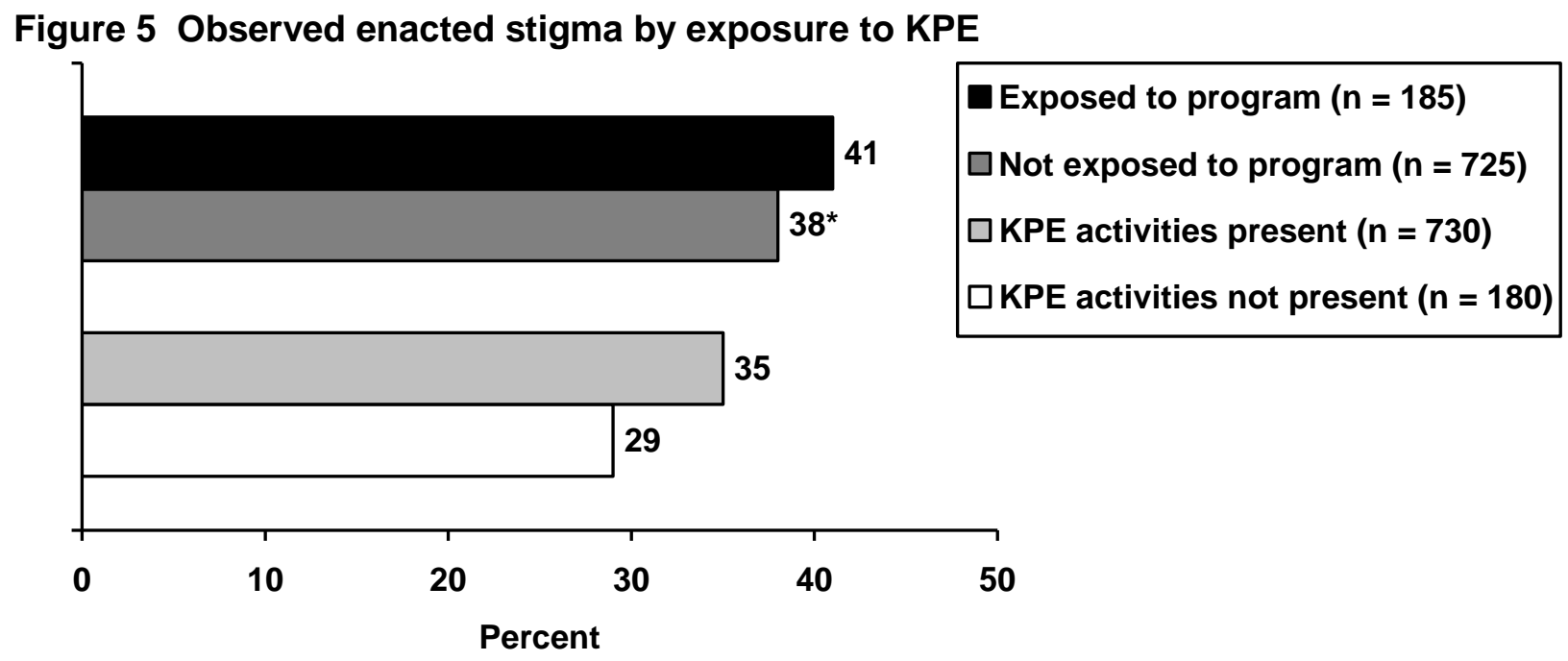

Note: \% reporting personal knowledge of incident occurring in Kimara in last 12 months ${ }^{*} \mathrm{p} \leq 0.05$

\section{Balozi Leaders are a Promising Entry Point for Intervention.}

Balozi leaders went through the two-week anti-stigma training, and KPE provided them ongoing support to integrate stigma-reduction activities into their work and daily lives. Not only did the training provide participants with new learning and skills, but it also led to significant personal reflection and action. One balozi leader was moved to share with his wife what he was learning at the workshop, opening up dialogue between them that led to the joint decision to be tested together for HIV. Another training participant commented, "I wish I had been exposed to this kind of training earlier on. My parents wouldn't have died. I can feel that they suffered more out of actions and attitudes from all of us in the family rather than they did from the virus."

The qualitative transcripts show that change is most clearly apparent among this group in both value- and fear-driven stigma. For example, there was a more genuine acceptance of people living with HIV as "normal" and "just like us," as demonstrated in the following quote from one balozi leader:

I cannot say that it is a punishment from God because I look at things as if we are sailing in the same boat. You know there is no need of blaming them and pointing finger to them...one cannot feel ashamed because s/he is HIV infected.

The KPE process of intensive training and follow-up support to balozi leaders also allowed these community leaders to overcome their fears of contracting HIV through casual transmission. According to another respondent:

As I told you earlier on that I used to fear people who are infected... I heard that my best friend was HIV infected, and it was very difficult for me to go into her house to say hello. I did not step in that house until she died. After attending the seminars [KPE training] I realized what I did to my best friend and I felt very sad about my bad behavior. I could not go to her house because I was afraid that I might get the infection as well. 
The program has also catalyzed key actions among the balozi leaders, such as rallying their communities to respond to stigma when it happens and making referrals to appropriate services. For example, one balozi leader recounted finding out about a child living with HIV in her jurisdiction who was being stigmatized and treated badly by her family, and taking action: "I tried and succeeded to reverse the situation. The child, now, is being well cared for, receiving every support possible within the family. I did it because I was well trained on stigma."

Balozi leaders and their constituency liked the new participatory style of communication they adopted as a result of the training and follow up, because it allowed them to share concerns more openly, discuss how they could deal with the presented issue, and design a solution to the problem. They particularly appreciated being able to pick relevant exercises from the toolkit to use in their discussions around stigma with communities and in meetings.

The KPE program was particularly effective among balozi leaders for two reasons. First, because the training and ongoing interactions between KPE and the balozis afforded them the opportunity to reflect on the importance of stigma in their own lives and communities and provided them with the skills and support necessary to act. Secondly, balozi leaders play a unique role in Tanzanian society that positions them to be opinion setters, advocates, mediators, and resource persons. The data show that balozi leaders used their new-found knowledge and applied the status of their position to advocate on behalf of persons with HIV living in their neighborhoods and ensure that their needs were met. For example, one trained balozi leader actively rallied her neighbors to contribute funds to ensure a neighbor living with HIV could buy needed medicines.

That the program was so transformative for the participating balozi leaders indicates promise for positive outcomes from wider training of balozi leaders and other types of community leaders.

\section{The KPE Program Did Not Reduce Stigma Community Wide.}

KPE conducted training and capacity building on stigma and discrimination for Kimara volunteer staff (56), people living with HIV (24), and ten local political community leaders (balozi) so that they would be able to recognize stigma and discrimination in their own lives and work, challenge stigma and discrimination when it happens, and advocate for change in the attitudes and behaviors that led to the stigma and discrimination. As noted above, the training was transformative on an individual basis for the balozi leaders, as well as for the other participants, and their efforts in the community resulted in lower levels of stigma among those individuals that they interacted with through intervention activities.

However, endline levels of stigma remained high, despite the presence of KPE anti-stigma activities in the community. In comparing levels of stigma drivers in clusters where KPE was present to clusters where it was not, there was no statistically significant difference at the community level (see Figure 6). On average, the number fears of respondents living in clusters where KPE was present (2.36) was about equal to the number of fears of respondents residing in clusters where KPE was not active (2.53). The mere presence of KPE's activities was not sufficient to cause ripple effects and foster positive outcomes among individuals not directly exposed to the intervention. 


\section{Hgrizons}

Figure 6 Fear and value-drive stigma at endline by KPE presence

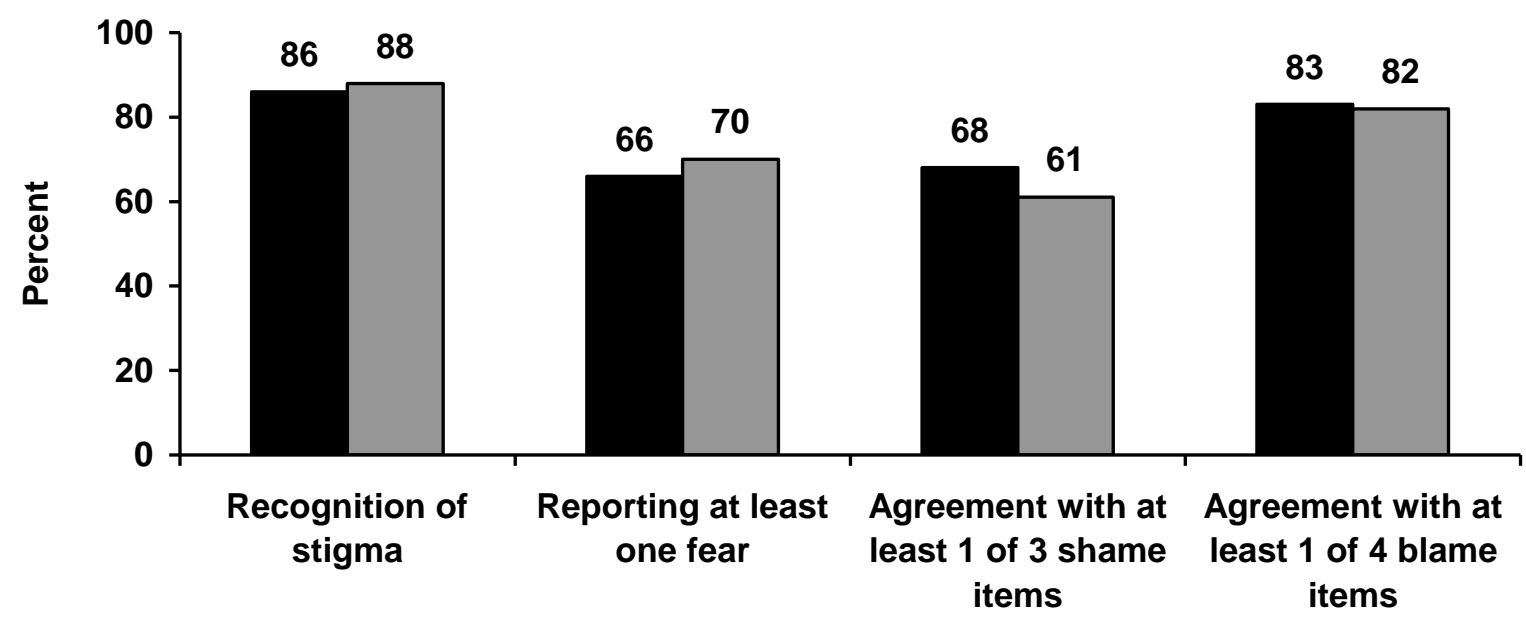

KPE activities not present $(n=180)$

$\square$ KPE activities present $(n=730)$

\section{The Stigma Indicators Performed Solidly Over Time.}

The study team repeated the same reliability and validity tests on the endline data that were conducted during the initial indicators testing (Tanzania stigma-indicators field testing group 2005) and concluded that these quantitative measures are reliable, valid, and appropriate for evaluation purposes. The indicators performed very similarly at both points in time. Nearly all items at endline continued to show variability and demonstrated test-retest reliability with very little discordance, as they had at initial testing.

Furthermore, the construction and reduction of scales and indices ${ }^{3}$ yielded nearly identical results. A fiveitem Fear Index was identified at baseline. Repeating this procedure at endline resulted in an index with identical items ${ }^{4}$. The study team recommended an eight-item Observed Enacted Stigma index at baseline, which retained at least one item in each form of stigma. At endline, a seven-item index emerged with much overlap with the items in the baseline index (see Table 2).

\footnotetext{
${ }^{3}$ From the full set of 12 fear items and 15 enacted stigma items, we dropped as many as we could without losing 10 percent of the total reporting at least one fear.

${ }^{4}$ These were items on fear of HIV infection through caring for someone with HIV, children playing with a child with HIV, and exposure to the sweat, saliva, and excreta of someone with HIV.
} 
Table 2 Items retained in the observed enacted stigma index at baseline and endline

\begin{tabular}{lcc}
\hline Item & $\begin{array}{c}\text { Retained at } \\
\text { baseline }\end{array}$ & $\begin{array}{c}\text { Retained at } \\
\text { endline }\end{array}$ \\
\hline Excluded from social gathering (exclusion) & $\checkmark$ & $\checkmark$ \\
Abandoned by spouse/partner (exclusion) & $\checkmark$ & $\checkmark$ \\
Abandoned by family/sent away to village (exclusion) & $\checkmark$ & $\checkmark$ \\
Isolated in household (exclusion) & & $\checkmark$ \\
Teased, insulted, or sworn at (verbal) & $\checkmark$ & $\checkmark$ \\
Gossiped about (verbal) & $\checkmark$ & $\checkmark$ \\
Lost respect/standing in family/community (identity) & $\checkmark$ & \\
Lost customers to buy produce/goods or lost job (institutional) & $\checkmark$ & $\checkmark$ \\
Had any type of property taken away & $\checkmark$ & \\
\hline
\end{tabular}

In a repeat of construct validity tests, the Fear Index and the Shame and Blame Scales demonstrated associations in the expected direction at baseline and endline. Correct knowledge of modes of transmission, means of prevention, and more in-depth knowledge of HIV were associated with fewer reports of fears. Respondents with higher education, in-depth knowledge about HIV, and proximity to persons living with HIV less frequently reported agreement with each item representing value-driven stigma $(\mathrm{p} \leq .05)$.

The construction of the Shame and Blame Scales resulted in the same seven items (three shame and four blame items) being used at both points in time ${ }^{5}$, but with a subtle difference. At initial testing, the seven values statements separated into two factors: (1) shame and (2) blame and judgment. At endline, the very same items loaded onto a single values factor instead of loading onto a shame factor and a blame factor separately (see Table 3). It appears that shame and blame converged into one concept for value-driven stigma.

\footnotetext{
${ }^{5}$ We performed principal components factor analysis using promax rotation to group items into similar categories (factors) and test internal consistency reliability.
} 


\section{Hgrizons}

Table 3 Factor loadings at baseline and endline: Shame and blame items

\begin{tabular}{|c|c|c|c|c|c|}
\hline \multirow[b]{2}{*}{ Stigmatizing attitude statement } & \multicolumn{3}{|c|}{ Baseline } & \multicolumn{2}{|c|}{ Endline } \\
\hline & $\begin{array}{l}\text { Rotated } \\
\text { factor } \\
\text { loadings }\end{array}$ & Shame & $\begin{array}{l}\text { Blame and } \\
\text { judgment }\end{array}$ & $\begin{array}{l}\text { Rotated } \\
\text { factor } \\
\text { loadings }\end{array}$ & $\begin{array}{l}\text { Shame, } \\
\text { blame and } \\
\text { judgment }\end{array}$ \\
\hline $\begin{array}{l}\text { I would feel ashamed if I was } \\
\text { infected with HIV }\end{array}$ & 0.884 & - & & 0.762 & - \\
\hline $\begin{array}{l}\text { I would be ashamed if someone in } \\
\text { my family had HIV/AIDS }\end{array}$ & 0.879 & - & & 0.809 & - \\
\hline $\begin{array}{l}\text { People with HIV/AIDS should be } \\
\text { ashamed of themselves }\end{array}$ & 0.777 & - & & 0.824 & - \\
\hline $\begin{array}{l}\text { People with HIV/AIDS are } \\
\text { promiscuous }\end{array}$ & 0.844 & & - & 0.736 & - \\
\hline $\begin{array}{l}\text { It is women prostitutes that spread } \\
\text { HIV }\end{array}$ & 0.824 & & - & 0.536 & - \\
\hline HIV is a punishment from God & 0.562 & & - & 0.630 & - \\
\hline $\begin{array}{l}\text { HIV/AIDS is a punishment for bad } \\
\text { behavior }\end{array}$ & 0.482 & & - & 0.762 & - \\
\hline Cronbach's alpha ${ }^{6}$ & & $\alpha=0.797$ & $\alpha=0.603$ & & $\alpha=0.850$ \\
\hline
\end{tabular}

Indeed, the qualitative data demonstrate that the two expressions of shame and blame appear alongside each other, are highly enmeshed, and are difficult to tease apart. While the study team had conceived of allocating responsibility for one's HIV status and judgments based on how one came to have HIV as part of the blame concept, the following quotes from endline focus group discussions conducted with male community members clearly connect this with shame.

You might feel ashamed when you find out how you contracted HIV...

I mean the majority of people will already have jumped to the conclusion regarding how a person contracted the disease. They do not care if a pregnant person got HIV from rape or from being promiscuous. They don't know if it was an accident. They automatically conclude it had to do with illicit sex...so there is no doubt that you will feel shame.

\section{New Measures for Care and Recognizing Stigma are Useful Improvements.}

In the course of this study, recognition of stigma, as measured by knowledge of the word "kunyanyapa," increased to as much as 96 percent in some groups. The lack of variability means that this measure may no longer capture further increases in the recognition of stigma. Where recognition of stigma is near universal, it is time to discard this measure in favor of a more nuanced one. The study team suggests asking respondents either to define stigma or to provide an example of stigma, and then assessing responses against some standard of a "correct" definition or example.

\footnotetext{
${ }^{6}$ Internal reliability with a $\alpha \geq 0.8$ is considered very good and $\alpha \geq 0.6$ is satisfactory.
} 
At endline, respondents were asked three nuanced questions about fear of HIV in terms of caring for an individual with HIV (see Table 4) to overcome ambiguities in the single baseline question. At baseline, respondents had interpreted "care" to mean anything from providing money or transport to health facilities to feeding, bathing, and treating sores for very ill patients. The study team suggests using one of the specific questions used during the endline that is most relevant to the setting.

Table 4 Fear items for caring for a person with HIV at baseline and endline

\begin{tabular}{|c|c|c|c|}
\hline \multicolumn{2}{|l|}{ Baseline } & \multicolumn{2}{|l|}{ Endline } \\
\hline Item & $\%$ with fear & Item & $\%$ with fear \\
\hline \multirow[t]{3}{*}{$\begin{array}{l}\text {...caring for a person living } \\
\text { with HIV/AIDS }\end{array}$} & 15 & $\begin{array}{l}\text {...caring for a person living with } \\
\text { HIV/AIDS who was not showing any } \\
\text { signs/symptoms, such as by preparing } \\
\text { meals, cleaning dishes \& utensils, sitting } \\
\text { near, and touching? }\end{array}$ & 12 \\
\hline & & $\begin{array}{l}\text {...And what about if they were showing } \\
\text { signs/symptoms at the time? }\end{array}$ & 24 \\
\hline & & $\begin{array}{l}\text {...caring for a person living with } \\
\text { HIV/AIDS such as by bathing and } \\
\text { dressing, washing soiled clothing or } \\
\text { bedding, cleaning vomit or diarrhea? }\end{array}$ & 43 \\
\hline
\end{tabular}

The study team also tested new fear items (particularly around exposure to blood, which was an expressed concern in this context), enacted stigma items, and shame and blame attitudinal statements. Neither the blood items nor any other additional items were retained in their respective indices or scales. These "improvements" that were tested did not significantly improve already well-performing measures. 


\section{Hgrizons}

\section{Discussion and Next Steps}

The findings of this study present a mixed, but hopeful, picture for a way forward in tackling stigma at the community level. In the face of what appears to be rising stigma in the community (Kimara) in general, respondents exposed to the KPE program had better stigma outcomes than their non-exposed counterparts at endline. In particular, there was a trend toward reduced value-driven stigma (i.e., shame) among exposed Kimara residents compared to non-exposed residents. Enacted stigma, or discrimination, that was observed by respondents was reported to increase over time, particularly in areas where KPE was active, which may be due to increased recognition of stigma and hence increased reporting.

The intervention evaluated here covered the first two-year period of a longer-term effort by KPE to reduce stigma in the communities they serve, and had the stated purpose of laying the foundation for a long-term effort. This foundation was laid through an initial stigma-reduction training of KPE volunteer staff, people living with HIV, and a small number of community political leaders (balozi leaders). Follow-on support for trainees to integrate stigma-reduction into their daily work and personal lives was also provided.

The power of the training to catalyze individual action was reflected in the interviews of the trained balozi leaders, who described examples in which they rallied their constituencies to challenge stigma and helped people living with HIV. They also described how the training allowed them to recognize stigma in their own actions and lives, and provided the motivation, confidence, and skills to make personal changes and work publicly to challenge stigma. The training also reinforced the need to "start at home" with stigma reduction, as often there is the incorrect assumption that front-line HIV workers, as well as persons living with HIV, recognize, understand, and know how to tackle stigma. Rarely are front-line workers given the safe space, support, and skills needed to reflect, understand, and deal with stigma happening in their own personal and professional lives.

On the community level, as opposed to the individual level, the evaluation did not demonstrate change, perhaps due to an insufficient level of coverage and/or length of the intervention. From the process data, it is clear that KPE was stretched very thin for the size of the population they were expected to cover. The original expectation was that in the two-year period, those who underwent the intensive stigma-reduction training would cover the whole of Kinondoni district (with more than one million people), as opposed to just Kimara Ward, where the baseline and endline surveys were conducted. Because of this expectation, those trained in stigma reduction conducted activities both inside Kimara Ward and in greater Kinondoni district, thereby diluting possible effects in Kimara ward whose residents participated in the pre- and postsurveys.

There are several additional limitations to this study that should be noted. First, the study collected qualitative data at one data point only, after the completion of the two-year intervention. There is no qualitative data on the state of HIV stigma in Kimara ward from baseline with which to compare the endline data. Instead, the study captured changes in stigma in the community by asking retrospectively at endline, which may introduce problems of recall. Second, the program evaluation used a pre/post study design. It lacked a control site, which would have been useful to assess confounding factors and distinguish effects of the stigma reduction program from other activities that could have affected stigma in the community. Third, a broad sampling frame was used for the quantitative survey.

The study team selected respondents from throughout Kimara ward, whereas the KPE intervention was never able to fully saturate the entire ward, partly because of expectations to also work in Kinondoni 
district. The study size was designed to detect at least a change of 10 percentage points among various stigma outcomes. However, it may have been unrealistic to expect KPE's intervention, which was covering the whole of Kinondoni district with less than a hundred trained individuals, to achieve a 10 percent reduction in stigma outcomes community-wide. It may have been more appropriate to sample clusters only from among those clusters where KPE implemented its activities more intensively. This was, in some respects, an artifact of the study in which each piece of the data collection was implemented in three separate phases, each with its own slightly distinct purpose.

\section{Lessons Learned}

While the official funding for KPE's initial stigma-reduction program ended in March 2006, KPE's volunteer staff, as well as trained balozi leaders and persons living with HIV, continue to work on reducing stigma through their work and personal lives. KPE has also secured new funding to continue work on reducing stigma in Kimara ward. In the two key informant interviews with the director of KPE, and the director of the current anti-stigma project, they both noted the challenges faced during this startup phase of KPE's stigma reduction efforts. Based on this experience, several key lessons learned are already being applied as KPE moves forward.

The first lesson learned is that tackling stigma requires that the individuals tasked with doing this undergo personal change, whether they be a veteran provider of HIV services or a community leader. The participatory training approach and toolkit worked well in this respect and are key to providing the tools and space to process, reflect, and learn about stigma to become an anti-stigma advocate within one's own sphere of influence.

The second is to start by focusing stigma-reduction efforts on a small, more manageable geographical area. KPE is now concentrating anti-stigma efforts on Kimara Ward. The third is to add a specific antistigma component, in addition to integrating stigma messages into all ongoing program activities, due to concerns that the stigma messages may have been too diffuse.

Fourth, the positive results of training the balozi leaders, and in particular the ability of these leaders to influence their constituencies, points to engaging community opinion leaders (e.g., political, religious, and youth leaders, and health care workers) as a promising way forward for scaling up stigma-reduction at the community level. KPE has already secured funding to expand the training of additional balozi leaders as well as to begin working with new groups of community leaders (e.g., faith leaders). 


\section{Hgrizons}

\section{References}

APN+. 2004. AIDS Discrimination in Asia: Asia Pacific Network of People living with HIV/AIDS.

Bond, V. et al. 2002. "Stigma, HIV/AIDS and Prevention and Mother-to-Child Transmission in Zambia." Evaluation and Program Planning 25(4): 347-56.

Brown, L. et al. 2003. "Interventions to Reduce HIV/AIDS Stigma: What Have We Learned?" AIDS Education and Prevention 15(1): 49-69.

Campbell, C. et al. 2005. Understanding and Challenging HIV/AIDS Stigma. HIVAN Community Booklet Series. (HIVAN), CfHAN. Durban: University of Kwa-Zulu Natal.

Carael, M. et al. 2000. Protocol for the Identification of Discrimination Against People Living with HIV. Geneva, Switzerland: UNAIDS.

Chen, J. et al. 2005. "Community environment and HIV/AIDS-related stigma," AIDS Education and Prevention 17(1): 1-11.

Deacon, H. 2006. Towards a Sustainable Theory of Health-Related Stigma: Lessons from the HIV/AIDS Literature., Journal of Community \& Applied Social Psychology 16: 418-425.

Goffman, E. 1963. Stigma: Notes on the Management of Spoiled Identity. New York: Simon \& Schuster Inc.

Heijnders, M. and S. van der Meij. 2006. "The fight against stigma: An overview of stigma-reduction strategies and interventions," Psychology, Health and Medicine 11(3): 353-63.

Hong, Y. et al. 2006. "Rural-to-urban migrants and the HIV epidemic in China," AIDS and Behavior 10(4): 421-30.

ICRW. 2006. "Reducing HIV/AIDS stigma, discrimination and gender-based violence among health care providers in Andhra Pradesh, India," Information Bulletin. Washington, DC: ICRW

Kalichman, S.C. et al. 2005. "Development of a brief scale to measure AIDS-related stigma in South Africa," AIDS and Behavior 9(2): 135-43.

Kalichman, S.C. et al. 2006. "Generalizing a model of health behavior change and AIDS stigma for use with sexually transmitted infection clinic patients in Cape Town, South Africa," AIDS Care 18(3): 17882.

Kidd, R. and S. Clay. 2003. Understanding and Challenging HIV Stigma: Toolkit for Action. Washington, DC: CHANGE Project, AED, and ICRW.

Link, B. and J. Phelan. 2001. On Stigma and Its Public Health Implications. Stigma and Global Health: Developing a Research Agenda. Washington, DC, National Institutes of Health. 
Liu, H. et al. 2006. "Understanding interrelationships among HIV-related stigma, concern about HIV infection, and intent to disclose HIV serostatus: a pretest-posttest study in a rural area of eastern China," AIDS Patient Care and STDs 20(2): 133-42.

MacQueen, K.M. et al. 1998. "Codebook development for team-based qualitative analysis," Cultural Anthropology Methods Journal 10: 31-36.

Madan, Y. et al. 2006. "Active involvement of PLAs to design and develop mass media campaign to address stigma and discrimination related to HIV and AIDS, PSI Zimbabwe," poster presented at PEPFAR Annual Meeting, Durban, South Africa.

Mahendra, V.S. et al. 2006. "Reducing AIDS-related stigma and discrimination in Indian hospitals," Horizons Final Report. New Delhi: Population Council.

Mills, E.A. 2006. "Briefing - From the Physical Self to the Social Body: Expressions and Effects of HIVRelated Stigma in South Africa." Journal of Community \& Applied Social Psychology 16: 498-503.

Nyblade, L. 2006. "Measuring HIV stigma: Existing knowledge and gaps," Psychology, Health and Medicine 11(3): 335-45.

Nyblade, L. and K. MacQuarrie. 2006. "Can we measure HIV/AIDS-related stigma and discrimination?: Current knowledge about quantifying stigma in developing countries.” Washington, D.C.: USAID.

Nyblade, L. et al. 2003. "Disentangling HIV and AIDS stigma in Ethiopia, Tanzania and Zambia." Washington, DC: ICRW.

Nyblade, L.C. and M.L. Field. 2000. "Women, communities and the prevention of mother-to-child transmission of HIV: Issues and findings from community research in Botswana and Zambia," ICRW Report-in-Brief. Washington: International Center for Research on Women.

Oanh, K.T.H. et al. 2008. "Improving hospital-based quality of care in Vietnam by reducing HIV-related stigma and discrimination," Horizons Final Report. Washington: Population Council.

Ogden, J. and L. Nyblade. 2005. "Common at its core: HIV-related stigma across contexts." Washington, DC: International Center for Research on Women.

Parker, R. and P. Aggleton. 2003. "HIV and AIDS-related stigma and discrimination: a conceptual framework and implications for action," Social Science \& Medicine 57(1): 13-24.

Ryan, G. and H.R. Bernard. 2003. "Techniques to identify themes," Field Methods 15: 85-103.

Tanzania stigma-indicators field testing group. 2005. "Measuring HIV stigma: Results of a field test in Tanzania." Washington, DC: Synergy.

Ulin, P. et al. 2002. "Qualitative methods: A field guide for applied research in sexual and reproductive health.” Research Triangle Park, North Carolina: Family Health International. 


\section{Hgrizons}

UNAIDS. 2006a. "Supporting effective scaling up towards universal access: Staff guide." Geneva: UNAIDS.

\section{—. 2006b. "2006 report on the global AIDS epidemic." Geneva: UNAIDS.}

White, R.C. and R. Carr. 2005. "Homosexuality and HIV/AIDS stigma in Jamaica," Culture, Health \& Sexuality 7(4): 347-59.

Wolfe, W. et al. 2006. "Effects of HIV-related stigma among an early sample of patients receiving antiretroviral therapy in Botswana," AIDS Care 18(8): 931-33.

Yoddumnern-Attig, B. et al. 2004. "HIV positive voices in Thailand: Their voices and choices." London: The International Community of Women Living with HIV/AIDS. 


\section{Appendix 1 Stigma Measures}

\section{Fear}

We asked respondents if they feared HIV infection through 11 specific means:

- If you touch the saliva of a person with HIV or AIDS

- If you touch the sweat of a person with HIV or AIDS

- If you touch the excreta of a person with HIV or AIDS

- [That your child would become infected with HIV] if they play with a child who has HIV or AIDS

- If you eat food prepared by a person with HIV or AIDS

- If you touch a person living with HIV or AIDS

- If you sleep in the same room as a person living with HIV or AIDS

- If you share eating utensils with a person living with HIV or AIDS

- If you stay near someone who is showing signs of HIV or AIDS

- If you sleep in a bed where a person living with HIV or AIDS previously slept

- If you share a toilet with a person living with HIV or AIDS

From these 11 items, we created an index and calculated the number of fears respondents held and compared their means. As a second summary measure, we calculated the proportion of respondents who had at least one fear.

\section{Shame and Blame}

We asked respondents if they agreed, disagreed, or were neutral to seven attitudinal statements capturing shame (3) and blame and judgment (4). These were:

\section{Shame}

- I would feel ashamed if I was infected with HIV

- People with HIV/AIDS should be ashamed of themselves

- I would be ashamed if someone in my family had HIV/AIDS

\section{Blame and Judgment}

- It is the women prostitutes that spread HIV in our community

- HIV is a punishment for bad behavior

- People with HIV/AIDS are promiscuous

- HIV is a punishment from God

From these individual items, we calculated two summary measures (1) agreement with at least one of three shame statements and (2) agreement with at least one of four blame statements.

\section{Recognition of Stigma}

The primary measure for recognizing stigma was a direct question asking if respondents knew the meaning of the Kiswahili word "kunyanyapa" (stigma). Respondents also provided a definition of "kunyanyapa" and described an example of stigma. 


\section{${ }^{H}$ rizons}

\section{Observed Enacted Stigma}

We did not inquire if respondents experienced enacted HIV stigma, as that would imply an HIV-positive status and for ethical reasons we did not request that respondents disclose their HIV status. We did not ask if respondents acted in stigmatizing ways, as we believed responses would suffer from social desirability bias. Instead, respondents told us if they personally knew someone within their community who was stigmatized in the last 12 months because they were known or suspected of having HIV or AIDS.

Observed enacted stigma was assessed through examples of stigma from four different forms:

Isolation-Physical and social exclusion/violence

- Excluded from a social gathering

- Abandoned by partner

- Abandoned by family/sent away

- No longer visited

- Isolated in household

- Physically assaulted

- Threatened with physical violence

\section{$\underline{\text { Verbal Stigma }}$}

- Voyeurism: visitors increased to "check out"7

- Teased, insulted, sworn at

- Gossiped about

\section{Loss of identity/role}

- Lost respect/standing within the family and/or community

- Denied religious rites/services

Loss of access to resources

- Lost customers or a job

- Denied promotion/training

- Lost housing

- Given poorer quality health services

- Had property taken away

A summary measure was created for each form of stigma (exclusion, verbal, loss of identity, and institutional stigma) and for observed enacted stigma overall (at least one of all 17 items).

\footnotetext{
${ }^{7}$ This type of voyeuristic stigma was frequently reported in the qualitative study as visiting someone with HIV/AIDS with the express intent of reporting back to the community, spreading rumors, and making fun of the person.
} 


\section{Hgrizons}

Horizons is a global operations research program designed to:

- Identify and test potential strategies to improve HIV/AIDS prevention, care, and support programs and service delivery.

- Disseminate best practices and utilize findings with a view toward scaling up successful interventions.

\section{(2) Population Council}

Horizons is implemented by the Population Council in collaboration with

- International Center for Research on Women (ICRW)

- International HIV/AIDS Alliance

- PATH

- Tulane University

- Family Health International (FHI)

- Johns Hopkins University

For more information, please contact:

Horizons Program, Communications Unit 4301 Connecticut Avenue, NW Suite 280 Washington, DC 20008 USA

Tel: 202-237-9400

Fax: 202-237-8410

Email: horizons@popcouncil.org www.popcouncil.org/horizons 